\title{
CONTRIBUIÇÕES DAS TECNOLOGIAS DA INFORMAÇÃO E COMUNICAÇÃO NA EDUCAÇÃO AMBIENTAL EM RESÍDUOS SÓLIDOS URBANOS AOS DISCENTES DA INSTITUIÇÃO PÚBLICA DE ENSINO.
}

\author{
Fábio Juvenal de Oliveira \\ Universidade Federal Fluminense - UFF \\ fabiolive21@gmail.com \\ Luis Perez Zotes \\ Universidade Federal Fluminense - UFF \\ lpzotes@gmail.com
}

\section{Resumo}

Destacando-se a relação existente entre a Política Nacional de Resíduos Sólidos - PNRS, e a Política Nacional de Educação Ambiental - PNEA, o presente trabalho aborda a importância das Tecnologias da Informação e Comunicação (TIC) integradas à mediação da educação ambiental em resíduos sólidos urbanos (RSU) aos discentes na IES. Este estudo possui característica qualitativa e a pesquisa bibliográfica foi realizada por meio de uma revisão de literatura, nas bases de dados eletrônicos SciELO.ORG; SciELO Citation Index; Scopus, além do uso de dissertações, livros e documentos. Os achados apresentados, demonstram que as TIC e a plataforma digital temática ambiental são ferramentas positivas,viabilizam e ampliam o ensino da educação ambiental em RSU na IES, ao interagir espaços educacionais reais e virtuais .

Palavras-Chave: TIC, Realidade Aumentada, Educação Ambiental, Resíduos Sólidos Urbanos, IES. 


\section{Introdução}

A geração anual mundial de resíduos sólidos urbanos (RSU) deve aumentar dos 2,01 bilhões, em 2018, para 3,40 bilhões de toneladas até 2050(KAZA et al.,2018). No entanto, segundo os mesmos autores, pelo menos $33 \%$ disso não é gerenciado em uma maneira ambientalmente segura. Cada brasileiro gera, em média, $1 \mathrm{~kg}$ de (RSU) por dia, a partir do que, estima-se que a população brasileira gere aproximadamente 79 milhões de toneladas de RSU por ano, sendo que apenas uma parte desse montante é destinada de forma ambientalmente adequada (BRASIL,2019).

Apesar de passados dez anos da vigência da PNRS, o setor ainda apresenta alguns déficits consideráveis, principalmente no tocante a coleta seletiva, recuperação de materiais e disposição final dos resíduos coletados (ABRELPE,2019). De fato, a PNRS precisa da colaboração das ações da Educação Ambiental (EA) para que promova a sensibilização das pessoas para "a não geração, a redução, a reutilização e a reciclagem de resíduos sólidos (GOBIRA et al.,2017).

Através da busca de novos processos de disseminação destas ações e projetos educacionais, busca-se, com o apoio das TIC, uma melhor integração e difusão dos conteúdos e práticas no programa de coleta seletiva e enraizamento no aprendizado ambiental do discente. A tecnologia serve como uma ferramenta educacional de suporte, um objeto de apoio, na forma de materiais de aprendizagem digitais (DANIELLA et al.,2018). Os aplicativos de aprendizagem e a pedagogia que se baseiam nessas rotinas ajudam a ajudar a unir os ambientes formal e informal, situando oportunidades de aprendizado social nos contextos on-line do dia-a-dia dos alunos e apropriando interações de colegas em tópicos curriculares e extracurriculares (GREENHOW et all,2017).

A forma como os alunos organizam a sua aprendizagem e procuram informações acadêmicas deve ser considerada crucial para o seu desempenho acadêmico em geral. Assim, as necessidades de informação e comportamento de busca é pertinente para o desempenho acadêmico (NWAFOR et al.,2019).

Destarte, é necessário compreender as possibilidades e interações das tecnologias da informação e comunicação, no que se refere à educação ambiental em RSU na Instituição, para os discentes e futuros formandos na sociedade. O objetivo é apoiar e promover a educação ambiental na IES, com a mediação das TIC em uma plataforma temática digital de conteúdos educacionais em RSU. 


\section{Metodologia}

A pesquisa bibliográfica caracteriza-se como exploratória, já que o propósito primordial deste tipo de estudo é aprofundar uma ideia, constituir possibilidades e tornar o assunto mais familiar. A pesquisa bibliográfica é constituída por livros e artigos científicos em contraposição à diversidade de fontes possíveis numa pesquisa documental (GIL, 2002).

Lakatos e Marconi (2003) corroboram com esta afirmação ao argumentarem que a pesquisa bibliográfica é uma síntese dos principais trabalhos realizados sobre o tema, fornecendo dados atuais relevantes.

Para o desenvolvimento desta pesquisa realizou-se uma revisão da literatura nas bases SciELO e Scopus no Portal de Periódicos da Coordenação de Aperfeiçoamento de Pessoas de Nível Superior (CAPES). Além de dissertações e fontes documentais, com o propósito de fornecer o embasamento teórico necessário ao tema.

A pesquisa bibliográfica utilizou 55 artigos científicos publicados nos últimos 5 anos, obtidos nas bases de dados: SciELO.ORG; SciELO Citation Index e Scopus. As palavras-chave na língua inglesa foram usadas na busca nas bases: SciELO Citation Index e na base Scopus. E na língua portuguesa, na SciELO.ORG.

Devido à especificidade do tema, procurou-se selecionar os resultados com maior aderência ao tema da pesquisa, usando os termos: Gestão de resíduos Sólidos; Educação Ambiental; IES; Tecnologias da Informação e Comunicação: Realidade Aumentada. Acrescentaram-se livros e artigos, sem limites temporais, oriundos de referências bibliográficas da produção acadêmica analisada com o objetivo de apontar outras perspectivas.

\section{A Política Nacional de Resíduos Sólidos - PNRS}

Procurando criar mecanismos legais que possam induzir o poder público a adotar uma gestão adequada dos resíduos sólidos em relação aos aspectos ambientais, sociais, econômicos e sanitários, o governo federal sancionou, em 2010, a Política Nacional de Resíduos Sólidos (PNRS), por meio da lei $\mathrm{n}^{\circ} 12.305$ (BRASIL, 2010).

Esta lei reúne todo um conjunto de princípios, objetivos, instrumentos, diretrizes, metas e ações adotadas pelo governo federal, isoladamente ou em cooperação com os Estados, o Distrito Federal, os municípios ou empresas privadas. Buscam estabelecer um sistema de gestão de resíduos sólidos, dentre os quais se destaca promover, através de uma abordagem integrada, a 
observância da seguinte ordem de prioridade: "Não geração, redução, reutilização, reciclagem e tratamento dos resíduos sólidos (KLEIN et al., 2019).

A PNRS define como princípios a prevenção e a precaução, elencando uma priorização para a gestão e no gerenciamento dos resíduos sólidos (FIRJAN,2019).

\section{A Política Nacional de Educação Ambiental}

Para a grande parte das questões de políticas e gestão de meio ambiente, o diálogo com a sociedade é feito com base em campanhas por parte dos governos.

A Lei Federal 9.795/99, que dispõe sobre a Educação Ambiental, instituiu a Política Nacional de Educação Ambiental (PNEA). O Órgão Gestor desta política, por ela estabelecido (Ministério do Meio Ambiente e Ministério da Educação) recria, em 2003, o Programa Nacional de Educação Ambiental (PRONEA) (BRASIL 2008).

De um modo geral, esta legislação, versa sobre os parâmetros gerais e a importância da Educação Ambiental (EA).

\section{A Educação ambiental e a aprendizagem digital}

De acordo com Cebrián et al. (2015), o ensino no campo da sustentabilidade ambiental exige "conhecimento, habilidades práticas, ferramentas, atitudes e valores éticos". Segundo Buchanan et al. (2019) estas 'Ferramentas' incluem as TIC, as ferramentas utilizadas devem melhorar um ou mais dos outros quatro aspectos mencionados: conhecimento, habilidades práticas, atitudes e valores éticos (CEBRIÁN et al.,2015).

A educação não é imune a avanços na sofisticada tecnologia da informação e comunicação (DANIELA et al.,2018).

A complexidade de conceituar cultura digital é discutida por Iannone, Almeida e Valente (2016, p. 57), quando evidenciam que "não é a tecnologia que determina ou contribui para a evolução da cultura digital (...) o que se identifica como cultura digital deve ser reconhecido a partir do recente desenvolvimento tecnológico e de outros conhecimentos que foram construídos". Os autores explicam que:

A escola que participa da cultura digital e dialoga com ela assume papel central na formação de estudantes com autonomia para tomar decisões, argumentar em defesa de suas ideias, trabalharem em grupo, atuar de forma ativa e questionadora diante dos acontecimentos, dificuldades e desafios, e participar do movimento de transformação social. Nesta escola, o potencial das TIC é incorporado às suas práticas por meio da exploração da mobilidade, da conexão e da multimodalidade, para permitir a autoria do estudante, que busca informações em distintas fontes; estabelece novas relações entre as informações, os conhecimentos sistematizados e aqueles que emergem das 
conexões nas redes ou são gerados nas experiências de vida; (reconstrói) conhecimentos representados por meio de múltiplas linguagens e de estruturas não lineares; interage e trabalha em colaboração com pares e especialistas situados em distintos lugares (IANNONE et al., 2016, p. 62).

\section{A Educação Ambiental não formal}

A educação ambiental se faz valer tanto de maneira formal, permeando as várias disciplinas das instituições de ensino, como não-formal, por meio da sensibilização da coletividade sobre as questões ambientais e estímulo a sua organização e participação na defesa da qualidade do meio ambiente (BRASIL,1999).

Caracterizar os espaços de educação não-formal não se constitui em tarefa simples, e, muitas vezes, os termos formal, não-formal e informal são utilizados de modo controverso fazendo com que suas definições estejam ainda longe de serem consensuais (MARANDINO,2017).

A educação não formal em nenhum momento compete com a educação formal e, sim, deve ser entendida como complementar as atividades escolares, sempre objetivando o fomento da cultura científica e tecnológica das pessoas, de modo geral (DE MORAES et al.,2017).

Esta trajetória de pensamento se faz contínua entre as modalidades educacionais, desenvolvidas em diferentes espaços, organizações, de forma integrada ou separadamente(MARANDINO,2017), sendo que as diferentes estratégias e práticas educacionais transitam em algum momento entre o formal, não-formal ou informal, em maior ou menor grau(DE MORAES et al.,2017).Tais contextos educacionais são observados no quadro 1.

Quadro 1:A educação vista como uma continuidade de categorias flexíveis

\section{Contextos Educacionais}

Formal $<<<<<$ Não-formal $>>>>>$ Informal

\begin{tabular}{|c|c|c|}
\hline - Propósitos: & Geral, com certificação & $\begin{array}{l}\text { Específico, sem necessidade } \\
\text { de certificação }\end{array}$ \\
\hline - Organização do conhecimento: & Padronizada, acadêmica & Individualizada, prática \\
\hline - Tempo: & Longo prazo, contínuo, sequencial & Curto prazo, tempo parcial \\
\hline - Estrutura: & $\begin{array}{r}\text { Altamente estruturada, currículo } \\
\text { definido, atividade determina } \\
\text { perfil do aprendiz, baseada na } \\
\text { instituição, avaliativa }\end{array}$ & $\begin{array}{l}\text { Flexível, ausência de currículo, } \\
\text { aprendiz determina perfil da } \\
\text { atividade, relacionada à comunidade, } \\
\text { não avaliativa }\end{array}$ \\
\hline - Controle: & Externo, hierárquico & Interno, democrático \\
\hline - Intencionalidade: & Centrada no educador & Centrada no aprendiz \\
\hline
\end{tabular}

Fonte: Adaptado pelo Autor deste Trabalho de Marandino (2017) 


\section{Educação Ambiental e a Educomunicação}

Com a finalidade de fortalecer a ação educadora coletiva pela sustentabilidade surge a Educomunicação, que se apresenta como um conceito envolvendo a interconexão entre dois campos da ciência: comunicação e educação (ROCHA,2015).

O PRONEA adota, então, como uma de suas linhas de ação, a "Comunicação para a Educação Ambiental" e a descreve como: "produzir, gerir e disponibilizar, de forma interativa e dinâmica, as informações relativas à Educação Ambiental" (BRASIL 2008). Assim, a Educomunicação estimula práticas interdisciplinares na educação e a mídia, na sociedade contemporânea conectada por redes, a comunicação não é apenas um processo de notificação ou disseminação de informações, mas também uma complexa rede de relacionamentos que troca ideias, opiniões e experiências. (ROCHA,2015).

\section{As Tecnologias da Informação e Comunicação.}

As relações sociais, na atualidade, são formadas em boa parte com a utilização de diversos artefatos tecnológicos, as TIC (tecnologia da informação e comunicação), que correspondem a um conjunto de recursos tecnológicos integrados entre si (BRANDALISE,2019).

Visam favorecer e otimizar a organização da sociedade, ao mesmo tempo, porém, os avanços nas TIC criam desafios para o campo da educação (DANIELA et al.,2018).

Remete, a todo e qualquer tipo de tecnologia aliada à flexibilidade de acesso à internet, com o uso wireless e da computação nas nuvens (WIRTZ,2018), que trate informação e auxilie na comunicação. Podendo ser na forma de hardware, software, rede ou aparelhos móveis em geral. Dentre eles, os notebooks, tablets, especialmente o uso de tecnologias de comunicação móvel, como smartphones, que continua a crescer consideravelmente (WIRTZ et al.,2018).

A FGV em uma nova edição de sua pesquisa anual sobre uso de tecnologia, revelou que, hoje, são 220 milhões de celulares em funcionamento no país contra 207,6 milhões de habitantes, de acordo com os dados mais recentes do IBGE (FGV EASESP,2020). Indica que cerca de 70\% dos aparelhos usados para conexão com a internet em nosso país são smartphones (FGV EASESP,2020). 


\section{TIC e o aprendizado digital}

O significado que as TIC têm na sociedade do conhecimento é consequência direta da digitalização, transmídia, crescimento exponencial das tecnologias e penetração da web 2.0(BARROSO-OSUNA et al.,2019).

A TIC como "análise de aprendizado", "gamificação", "videogames sérios" ou "robótica" estão sendo rapidamente incorporadas ao ensino (BARROSO-OSUNA et al.,2019). As realidades físicas e digitais são misturadas através de diferentes recursos, como imagens, diferentes objetos tridimensionais, incorporação de QR Code, leituras térmicas ou coordenadas GPS. (GARCIA,2016). Ou qualquer outra forma contemporânea de transmissão e ferramentas tecnológicas com fins educacionais, que devem ser considerados e interligados. Nessa direção, os meios de comunicação, sobretudo, as redes sociais e aplicativos são significativos no auxílio desta tarefa, principalmente por terem um alto alcance de público em pouco tempo (STEFANI et al.,2016).

\section{A Realidade Aumentada}

De acordo com Cabero-Almenara et al. (2019), a Realidade Aumentada (RA) é uma tecnologia emergente que está ganhando maior influência no ensino todos os dias. Em sinergia com a tecnologia móvel, é definida como um dos pares mais eficientes para apoiar um aprendizado significativo e onipresente.

Os objetos RA se adaptam às características dos dispositivos em que serão visualizados. Em termos de conteúdo, devem ser curtos e diretos, com duração não superior a 5 minutos, devem considerar as diferentes capacidades dos alunos, as atividades devem ser apresentadas com uma interface intuitiva (BARROSO-OSUNA et al.,2019).

Em comparação com outras tecnologias a RA, possui uma série de características específicas (BARROSO-OSUNA et al.,2019):

- Ser de realidade mista, permitindo o enriquecimento ou complementação da informação da realidade com a informação digital.

- A integração ocorre em tempo real e de maneira coesa.

- Facilita a unificação de diferentes recursos: texto, sites, videoclipe, áudio e 3D.

- É interativo.

- Na criação de conteúdo, é necessária a intervenção de uma pessoa. 


\section{As TIC na Educação Ambiental nas IES.}

As plataformas de mídia social são cada vez mais acessadas por meio de aplicativos de telefonia móvel, permitindo que os usuários se conectem às mídias sociais a qualquer momento e em qualquer lugar (PEARSON et al.,2016).

Nas IES geralmente são disponibilizados e divulgados links de sítios eletrônicos com temas correlatos à EA em coleta seletiva nos próprios equipamentos tecnológicos ou no painel de avisos. A comunidade acadêmica que circula pelo Campus deve ser educada a interagir acessando o QR CODE (figura 1) presente em cartazes, banners, pontos de descarte de resíduos distribuídos na instituição.

Figura 1 - Código QR Code e processo de leitura na tela do celular
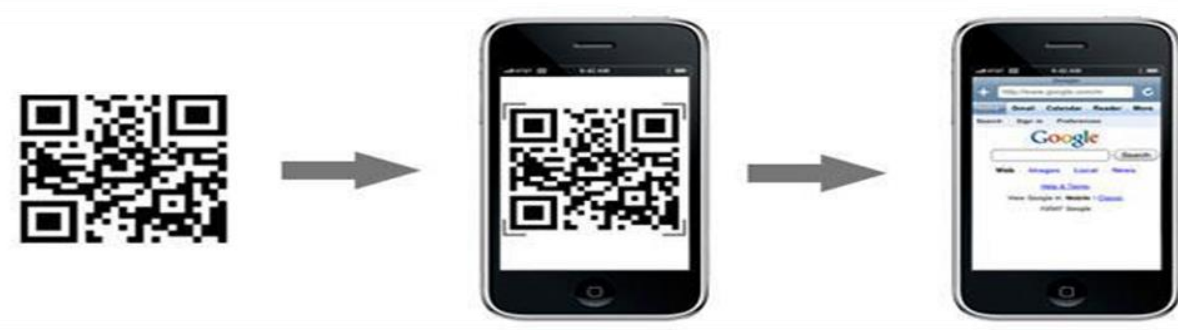

Fonte: Iphone dicas, em: http://iphonedicas.com.

Como a TIC abrange e permite ser usada em vários contextos, ela é potencializada para fazer o tratamento da informação, auxiliando o gestor ambiental a alcançar um determinado objetivo, como por exemplo o mapeamento, com conteúdo educacional, orientando aos discentes os locais dos diversos tipos de descarte existentes na IES (figura 2).

Figura 2- Potencial tratamento da informação com QR Code.

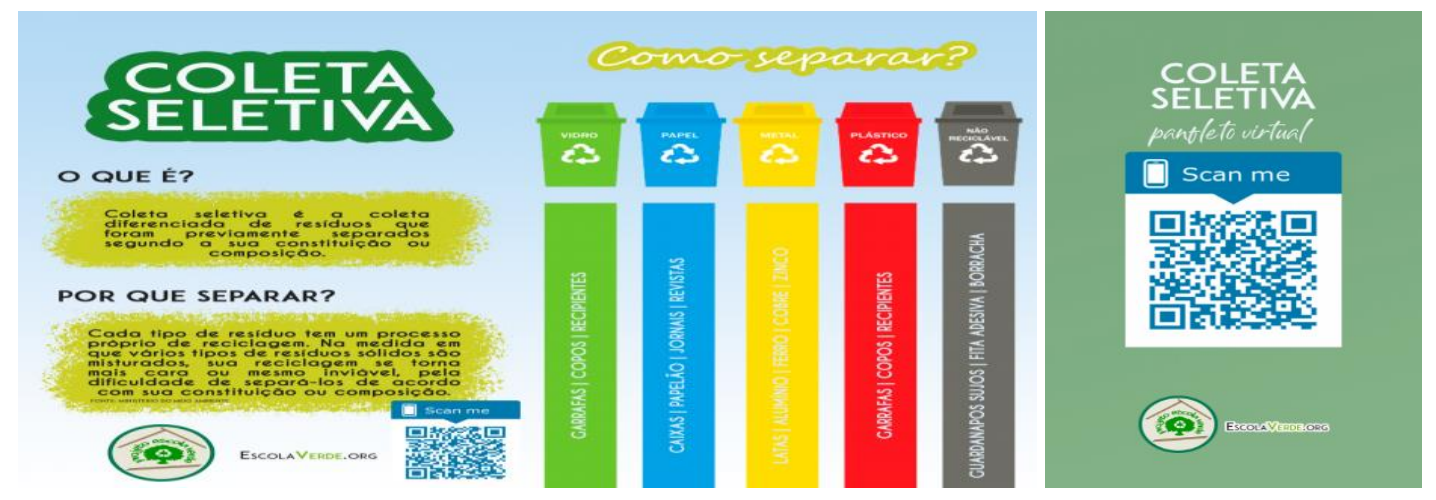

Fonte: Projeto Escola Verde, em: https://escolaverde.org/site 
As TIC combinadas de forma adequada e criativa promovem a educação ambiental em descarte seletivo na IES, interagindo e convergindo à plataforma digital nesta temática de RSU, pois tem, mediante a proposta deste estudo, a capacidade e potencial necessários ao desenvolvimento de diversos recursos de acesso gratuito a professores e estudantes na Web, como aulas em vídeo, áudio, multimídia, jogos, animações, mapas e outros tipos de objetos digitais de aprendizagem na temática resíduos sólidos urbanos. O papel dos educadores, preparados, comprometidos e dispostos a usar diferentes tecnologias para desenvolver o aprendizado, está no centro do processo educacional (DANIELA et al.,2018). Os repositórios de atividades educativas têm por característica a disponibilização de muitos recursos educacionais os quais permitem serem utilizados online ou "baixados". Eles armazenam também apenas o endereço, que remete aos objetos educacionais em RSU, os quais são direcionados para outros repositórios ou bancos.

\section{Discussão}

Conforme prevê o artigo 225 da Constituição Federal (BRASIL,1988), o poder público necessita dispor de instrumentos e programas que venham a confirmar a condição de defensor do meio ambiente. A comunicação digital de conteúdos educacionais em RSU é o mediador não formal, pelo qual, se viabiliza a conscientização, prática e a educação ambiental. Em relação à PNRS, à PNEA, ao PRONEA, e suas dimensões educacionais em descarte de resíduos sólidos urbanos na IES, a plataforma digital temática apresentada de forma criativa e didática, torna-se uma oportunidade para romper a falta de entendimento e consistência das aplicações de tais políticas aos discentes na IES. É necessário fazer o uso de instrumentos que facilitem a promoção desta sensibilização e aprendizado, convergindo tecnologias, mídias em diferentes espaços educativos, como por exemplo o QR Code e a RA. A Realidade Aumentada (RA) oferece a capacidade de se misturar e combinar dois ambientes: o físico e o digital, e tudo isso em tempo real, através do uso de tecnologias emergentes e de fácil acesso, como smartphones ou tablets (CABERO-ALMENARA et al.,2019). "A realidade aumentada introduz o conhecimento que o aluno deve aprender em seu ambiente do mundo real, de forma visível” (MAQUILÓN et al.,2017). As IES não funcionam no vácuo, elas estão situadas na sociedade e na cultura digital. A inovação tecnológica está atualmente ocorrendo em um ritmo sem precedentes na educação (CAMILLERI et all.,2017). O principal facilitador para a adoção e aplicação dos conceitos mencionados e das práticas e princípios a eles associados é o estímulo da cultura de redes no campo da comunicação educacional ambiental não-formal. A criação de 
aplicativos ou plataformas digitais contendo conteúdos explicativos e consistentes em RSU facilita as conexões entre os discentes na IES, entendimento das práticas ambientais em RSU, não se limitando a passar o conhecimento ambiental, mas informar como proceder e reduzir os riscos ambientais que afetam a vida. Devido a ampliação das condições e das possibilidades de uso de diferentes mídias no espaço virtual, o ciberespaço, a cultura digital cada vez mais se acentua na sociedade (BRANDALISE,2019). Estimula-se assim, a prática consciente para interação de problemas comunitários reais em RSU na IES, fortalecendo o sentido de pertencimento à comunidade acadêmica.

\section{Considerações finais}

Assim sendo, com base nas PNRS, PNEA, citações dos autores e discussões, percebe-se que, as TIC são ferramentas positivas para auxiliar no processo de ensino aprendizagem da educação ambiental em RSU. As TIC ainda que não estejam usualmente integradas e estabelecidas no cenário de educação ambiental não-formal, viabilizam que as partes interessadas construam na IES uma plataforma temática educacional ambiental em RSU, que contemplem: a convergência das mídias educacionais, tecnologias móveis e mobilidade, potencialidades comunicativas, redes sociais, ferramentas colaborativas e interativas e espaços tecnológicos convergentes. Esta união dos espaços educativos reais e virtuais na IES, em diferentes proporções, de forma híbrida, amplia o aprendizado de educação ambiental em RSU. A plataforma digital temática ambiental em RSU, promove a participação e compartilhamento do aprendizado ambiental aos discentes, apoiando a construção da educação ambiental, com uma visão sistêmica das implicações de suas atividades cotidianas na esfera da sustentabilidade ambiental em RSU na IES, e na sociedade. 


\section{Referências}

ASSOCIAÇÃO BRASILEIRA DE EMPRESAS DE LIMPEZA (ABRELPE). (2019) Panorama da gestão de resíduos sólidos no Brasil. São Paulo: ABRELPE. Panorama dos Resíduos Sólidos no Brasil 2019, fonte: http://abrelpe.org.br/download-panorama-2019/, acesso em janeiro de 2020.

BARROSO -OSUNA, Julio et al. Difficulties in the Incorporation of Augmented Reality in University Education: Visions from the Experts. Journal of New Approaches in Educational Research, [S.1.], v. 8, n. 2, p. 126-141, july 2019. ISSN 2254-7339. Disponível em: <https://naerjournal.ua.es/article/view/409>. Acesso em: 18 mar. 2020. doi:http://dx.doi.org/10.7821/naer.2019.7.409.

BRANDALISE, MARY ÂNGELA TEIXEIRA. TECNOLOGIAS DE INFORMAÇÃO E COMUNICAÇÃO NAS ESCOLAS PÚBLICAS PARANAENSES: AVALIAÇÃO DE UMA POLÍTICA EDUCACIONAL EM AÇÃO. Educ. rev., Belo Horizonte, v. 35, e206349, 2019. Disponível em: <http://www.scielo.br/scielo.php?script=sci_arttext\&pid=S0102-46982019-000100412\&lng=en\&nrm=iso>accesso em 27 de fev., 2020. https://doi-.org/10.1590/01024698-206349.

BRASIL. Constituição Federal, promulgada em 1988.

BRASIL. Ministério do Meio Ambiente. Lei n. 9.795/1999. Dispõe sobre a Educação Ambiental, institui a Política Nacional de Educação Ambiental e dá outras providências. Disponível em: <http://www.lei.adv.br/979599.htm>. Acesso em: 20 out 2019.

BRASIL. Ministério do Meio Ambiente. Secretaria de Articulação Institucional e Cidadania Ambiental. Programa Nacional de Educação Ambiental. Educomunicação socioambiental: comunicação popular e educação. Organização: Francisco de Assis Morais da Costa. Brasília: MMA, 2008.

BRASIL. Lei 12.305 de 2 de agosto de 2010. Institui a Política Nacional de Resíduos Sólidos; altera a Lei no 9.605, de 12 de fevereiro de 1998; e dá outras providências. Disponível em:

<http://www.planalto.gov.br/ccivil_03/_Ato2007-2010/2010/Lei/L12305.htm>. Acesso em: 20 de julho de 2019.

BRASIL. Ministério do Meio Ambiente. Agenda Nacional de Qualidade Ambiental Urbana: Programa Nacional Lixão Zero / Ministério do Meio Ambiente, Secretaria de Qualidade Ambiental, Departamento de Qualidade Ambiental e Gestão de Resíduos, Coordenação-Geral de Qualidade Ambiental e Gestão de Resíduos. - Brasília, DF: MMA, 2019.

BUCHANAN, J., Pressick-Kilborn, K., \& Maher, D. (2019). Promoção da educação ambiental para alunos em idade escolar que usam tecnologias digitais. Eurasia Journal of Mathematics, Science and Technology Education, 15 (2), em1661. https://doi.org/10.29333/ejmste/100639.

CABERO-ALMENARA, J.; Barroso-Osuna, J.; Llorente-Cejudo, C.; Fernández Martínez, MM Augmented Reality (AR) Educational Uses: Experiences in Educational Sciences. Sustainability 2019, 11, 4990.

CAMILLERI, M.A., Camilleri, A.C. Digital Learning Resources and Ubiquitous Technologies in Education. Tech Know Learn 22, 65-82 (2017). https://doi-org.ez24.periodicos.capes.gov.br/10.1007/s10758-016-9287-7.

CEBRIÁN G, Junyent M. Competencies in Education for Sustainable Development: Exploring the Student Teachers' Views. Sustainability. 2015; 7(3):2768-2786. Disponível em http://www.mdpi.com/20711050/7/3/2768 / html Acesso em: 20 dez. 2019.

DANIELA, L.; Visvizi, A.; Gutiérrez-Braojos, C.; Lytras, MD Educação Superior Sustentável e Aprendizagem Aprimorada por Tecnologia (TEL). Sustentabilidade 2018, 10, 3883.

DE MORAIS, Carina Siqueira; FERREIRA, Helaine Sivini. A Educação Não-Formal para a Promoção da Cultura Científica e Tecnológica no Ensino de Química e das Ciências. Revista Debates em Ensino de Química, v. 2, n. 2, p. 45-55, 2017.

FIRJAN. Manual de gerenciamento de resíduos / Firjan. - Rio de Janeiro: [s.n], 2019. 35 p.

FGV EAESP. Pesquisa Anual do Uso de T Disponível em https://eaesp.fgv.br/ensioeconhecimento/centros/cia/pesquisa. Acesso em 15 mar.2020.

GARCÍA, José Manuel Sánchez. Realidad aumentada: tecnologia para la formacion. Pixel-Bit, Revista de Medios y Educacion, n. 49, p. 241-243, 2016.

GIL, Antônio Carlos. Como elaborar projetos de pesquisa.4. ed. São Paulo: Atlas, 2009. 
GOBIRA, Ari Silva; LEITE, Eugênio Batista. Educação ambiental: uma ferramenta para plano de gerenciamento de resíduos. Sinapse Ambiental, v. 7, p. 33-53, 2010. Disponível em:

<http://www1.pucminas.br/graduacao/cursos/arquivos/ARE_ARQ_REVIS_ELETR20100

917093851.pdf?PHPSESSID=e93bc7c258ce94a0d6fe6bdb5ecce996> Acesso em: 20 dez. 2019.

GREENHOW, C., Askari, E. Learning and teaching with social network sites: A decade of research in K-12 related education. Educ Inf Technol 22, 623-645 (2017). Disponível em https://doi.org.ez24.peri-odicos.capes.gov.br/10.1007/s10639-015-9446-9 Acesso em: 22 dez. 2019.

IANNONE, L. R., Almeida, M. E., \& Valente, J. A. (2016). Pesquisa TIC Educação: Da inclusão para a cultura digital. In: Comitê Gestor da Internet no Brasil - CGI.br, Pesquisa sobre o uso das tecnologias de informação e comunicação nas escolas brasileiras: TIC Educação 2015. São Paulo: CGI.br.

IPHONEDICAS. Código QR Code e processo de leitura do na tela do celular.

Disponível em: 〈http://iphonedicas.com〉. Acesso em: 15 mar. 2020.

LAKATOS, Eva Maria; MARCONI, Marina de Andrade. Fundamentos de Metodologia científica. $5^{\text {a }}$ ed. São Paulo: Ed. Atlas. 2003.

KAZA, Silpa; Yao, Lisa C.; Bhada-Tata, Perinaz; Van Woerden, Frank. 2018. What a Waste 2.0: Uma visão global do gerenciamento de resíduos sólidos até 2050. Desenvolvimento Urbano; Washington, DC: Banco Mundial. @ Banco Mundial. https://openknowledge.worldbank.org/handle/10986/30317 Licença: CC BY 3.0 IGO. Acesso em: 20 fev. 2020.

KLEIN, Flávio Bordino; GONCALVES-DIAS, Sylmara Lopes Francelino; JAYO, Martin. Gestão de resíduos sólidos urbanos nos municípios da Bacia Hidrográfica do Alto Tietê: uma análise sobre o uso de TIC no acesso à informação governamental. urbe, Rev. Bras. Gest. Urbana Curitiba, v. 10, n. 1, p. 140-153, Apr. 2018.

Disponível em <http://www.scielo.-br/scielo.php?script=sci_arttext\&pid=S2175-

33692018000100140\&lng=en\&nrm=iso>. Acesso em: 20 jan. 2020. https://doi.org/10.1590/21753369.010.001.ao10.

MARANDINO, Martha. Faz sentido ainda propor a separação entre os termos educação formal, não formal e informal? Ciênc. educ. (Bauru), Bauru, v. 23, n. 4, p. 811-816, Dec. 2017. Available from <http://www.scielo.br/scielo.php?script=sci_arttext\&pid=S1516-73132017000400811\&lng=en\&nrm=iso>. Acesso em: 23 fev. 2020. https://doi.org/10.1590/1516-731320170030001.

MAQUILÓN, JJ; Mirete, A.; Avilés, M. La Realidad Aumentada (RA). Recursos e propostas para a inovação educacional. Rev. Interuniv. Formato. Profr. 2017, 20, 183-203.

NWAFOR, Michael Chigozie; Igbokwe, Josephine C.; Ali, Adizetu A.; e Onoh, Chioma C., "Level of Awareness and Information Needs on Indiscriminate Dumping of Solid Waste among Staff and Students at Nigerian Universities". (2019). Philosophy and Practice Library (e-journal). 2248.Disponível em https: //digitalcommons.unl.edu/libphilprac/2248 Acesso em: 20 dez. 2019.

PEARSON, E., Tindle, H., Ferguson, M., Ryan, J. \& Litchfield, C. Can we tweet, post, and share our way to a more sustainable society? A review of the current contributions and future potential of \#Socialmediaforsustainability. Annu. Rev. Environ. Resour. 41, 363-397 (2016).

PROJETO ESCOLA VERDE.2019. Disponível em https://escolaverde.org/site/?p=64391, acesso em $10 \mathrm{de}$ junho de 2020.

ROCHA, Paula Melani (2015) A IMPORTÂNCIA DA Educomunicação NA FORMAÇÃO DE PROFISSIONAIS Comunicação Social na contemporaneidade, Communicatio, 41: 2, 192-205, DOI: 10,1080 / 02500167.2015.1070186.

STEFANI, G., Bernardes, J. C., \& Bernardo, C. H. C. (2016). COMUNICAÇÃO E REDE AMBIENTAL: ANÁLISE DAS TICS UTILIZADAS PELO GRUPO DE PESQUISA EM GESTÃO E EDUCAÇÃO AMBIENTAL. Revista Científica ANAP Brasil, 9(14).

VIEIRA, Adriane Aparecida Vasconcelos. Tecnologia e comunicação nas instituições de ensino superior: o uso do SACI na UFSCar Dissertação (Mestrado). 2015.

WIRTZ, Bernd W.; BIRKMEYER, Steven. Mobile government services: An empirical analysis of mobile government attractiveness. International Journal of Public Administration, v. 41, n. 16, p. 1385-1395, 2018. 